\title{
EXPERIENCIA POÉTICA DE AULA FILOSÓFICA
}

Mauricio Langon

Esta introducción debía haberla hecho oralmente, porque escuchando las mesas y discusiones de estos días me convencí de que tenía que hacer algunas aclaraciones previas, como por ejemplo agradecer a Maxi (si él se agradeció, como no iba a agradecerle yo, que además le debo un paseo a la playa y algún pescadito y cangrejo), a Tarcísio, que me consiguió vestuario y duchas, y a los demás organizadores, por estos hermosos días con tantos amigos nuevos y viejos.

Pero salió escrita, mientras esperaba ayer que funcionara el sonido para la exposición de Silvia. Para evitar malos entendidos, me pareció necesario decir al menos desde dónde me ubico.

¿De qué hablamos aquí? ¿De la escuela? si es así ¿en qué sentido-? ¿de la educación? ¿del aprendizaje? ¿de la enseñanza? ¿de la filosofía? ¿de la educación filosófica? ¿de la poesía?

Yo me instalo en lo filosófico (cuyos rasgos me reservaré esta vez); ${ }^{i}$ en lo didáctico-filosófico-pedagógico; en el filosofar que vive en las aulas (en el más amplio y original sentido del término aula que abraca desde las cavernas o el lugar de los fogones guaraníes, hasta los Palacios Legislativos), y en otros espacios también humanos y por tanto, también aulas, como las plazas, los cafés, las esquinas, las calles.

Resulta que había pensado proponer aquí un par de líneas para pensar el vacío filosófico de nuestra educación: en nuestras escuelas, en los institutos secundarios, en las Universidades. Tanto en las carreras de formación docente, como en las carreras "de filosofía" se suele respirar un vacío filosófico. Como cualquier vacío, no es nunca mera nada: siempre está lleno de otras cosas (ondas, energías, partículas) que no son hacer filosofía, sino su contrario, o mejor, su enemigo. 
a. Una de las líneas que pensaba desarrollar, como aquí la cuestión tiene que ver con lo poético, la empecé a pensar primero como poiético y empecé a escribir algunas ideas sueltas (porque lo poético es soltarse). Y empecé a divagar sobre la poética y la estética (eso que tiene que ver con sentiry con sentido y que se opone a la anestesia) lo que me llevó al menos al algia y la analgesia, al dolor, a la ética, a la épica, la estética y a la patética. (Casi me salió interrumpiendo el tránsito). La estética de lo tenebroso. Maldoror. La necesidad de destapar lo tapado; aceptar y enfrentar. El filosofar des-consolado de Boecio. El encanto y el desencanto.

El canto. Y, por supuesto, la poíesis.

b. La segunda línea que tenía ganas de trabajar es que, como en un trabajo reciente había reflexionado sobre lo que podríamos llamar el "macroproducto" de toda la Ciencia y la Tecnología (es decir, todo eso que ahora tenemos y antes no teníamos, todas esas maravillosas posibilidades de vida), considerado -en su conjunto como un todo solidario, que abarca también la estructura económica que lo sostiene, posibilita y rige-, pero exclusivamente en sus aspectos positivos, excluyendo sistemáticamente sus necesarios efectos nefastos; y como advertí sutilmente que esos productos, que en su conjunto legitiman la bondad o al menos el acierto y la eficacia de las técnicas y los seres humanos que los fabrican o inventan, ahora resultan circularmente legitimados, en su cualidad, calidad y continuidad por las mismas normas técnicas cuya cualidad y calidad garantizan la continuidad de ese megaproducto, que pronto quedará obsoleto por el propio avance tecnológico... bueno... pensaba en desarrollar esa idea mostrando cómo afecta todo esto la experiencia poiética de una educación filosófica.

¿Verdad que no se entendió nada? Quiero decir, se vive como todo bueno lo que produce en su conjunto la Ciencia y la Tecnología. Es esa bondad del producto que justifica las técnicas adecuadas para lograrlo. Pero, hoy, son las normas técnicas previas las que van a garantizar la cualidad y la calidad de cada uno de los productos (incluso los poéticos y filosóficos). Pero, por ejemplo, en el 
hall vimos un viejo papelógrafo referido a cristalografía. Hoy, una norma técnica previa (que incluye normas formales, de producción, y normas de contenido, materiales) a la realización de cada producto determinará, por ejemplo, qué condiciones deberá tener el cristal que se usará para una ventanita como la que hay en el fondo de este salón (que permite ver y proyectar) y todos confiaremos que de ese proceso saldrá sin duda un buen cristal que sirva para esos usos. Pero las normas técnicas para cristales para botellas, copas de cristal, instrumentos que necesitarán resistir altas temperaturas o presiones en un laboratorio; serán normas totalmente distintas. Difieren sensiblemente según el uso a que esté destinado el cristal: para grandes ventanales de edificios elevados, para cápsulas espaciales, para vehículos blindados, para termómetros, para fundiciones... Para cada uso específico, sus normas técnicas propias. Pero, cuando regimos la actividad académica como si fueran normas técnicas, suponemos que la cualidad de cada producto -ser poesía, filosofía, pintura, matemática, química- dependerá del cumplimiento de esas normas, que básicamente son las mismas para los productos más diversos. Y nos ahorramos el trabajo de pensar de qué calidad sea el producto en cuestión, de discutirlo de cuestionarlo. Porque lo suponemos tan obsolescente como ese vidrio que cambiará seguramente dentro de pocos años. Y otros objetos más efímeros, como esta computadora, quedará rápidamente obsoleta, que ya es obsoleta, que ya compré obsoleta. Ya no compro computadoras porque quedan obsoletas. Porque suponemos erróneamente que en todos los casos tienen usos o aplicaciones únicos o unívocos o inmediatos. Porque suponemos erróneamente que la producción intelectual sigue una línea meramente acumulativa de avances en lo técnico (en los métodos) que permiten seguir produciendo productos cada vez más rápidamente obsoletos, cada vez más sustituibles por otros nuevos. Cuando en realidad involucra efectos de larguísimo alcance y variado $e$ imprevisible uso, que nunca quedan obsoletos y sobre los cuales queda abierta la posibilidad de debate en torno al carácter ético y político de sus eventuales aplicaciones). 
Quería trabajar sobre ese tipo de cosas porque me parecen importantes para pensar la experiencia poiética -que implica técnicas- de la educación filosófica.

Así que empecé a escribir algo sobre la idiota pérdida de la iota que nos acerca a poesía y poema (ya que no sólo a las técnicas para embellecerlos o hacerlos eficaces) a la vez que nos aleja de las ideas de "acción, creación; adopción; fabricación, confección, construcción; composición"; y de las acciones de "hacer, fabricar, ejecutar, construir; realizar, efectuar; engendrar, dar a luz, producir; obtener, sacar -algo de otra cosa-; poner -'un pensamiento en el alma', 'paz entre Armenios y Caldeos'-; volver a alguien insensato, hacerle perder el juicio; obrar, ser eficaz; crear, inventar, componer versos; suponer, representar, considerar como, juzgar"; y algunas otras cosas más, que significan poíesis y poiéo.

Después hice con todo esto un bollo que sólo desembrollo ahora, a modo de introducción, para que no sea malentendido como unilateral lo que sigue, que es lo que escribí. Que no sé si será filosófico, y menos si será poético. Pero que me fue "inspirado". Y voy a leer ahora más bien sin recortes, con reiteraciones, sin pulidos, contra una presunta "Filosofía sabia" que, como ya sabe lo que quiere, ya no quiere saber; y, por tanto, ya no es filosofía.

1.

“Cuántos ruiseñores debe devorar la bestia para poder cantar ella misma?"1

Pensemos aquí en La Filosofía como esa bestia agazapada en la puerta de su caverna acechando ignorantes infancias inocentes.

Es el Ñaupa Machu, desde su montaña que se llamaba "Escuela", que les dice a los hijos del Inka: “- 'Vengan, vengan, les voy a revelar dónde está el Inka y dónde está Mama Pacha'. Los niños contentos dicen que fueron a la escuela.

\footnotetext{
${ }^{1}$ El verso es de un poeta, claro. No necesita de éste para vivir, aunque sí para nacer. Lo escuché el sábado pasado en Buenos Aires, tras La Puerta. Es un argentino radicado en España que escribe en rioplatense, cuyo nombre espero que alguien me recuerde, aunque creo que es Martín. Le llamaban Poni, si mal no entendí. Nombre de bestia, al fin. Y canta.
} 
Naupa Machu quería comerlos". Y uno puede preguntarse, como el autor del texto: "¿se morirán de hambre?"2

Es, yendo más lejos -a las Uropas en tiempos del Naupa- la bruja mala del bosque quien, con "un hermoso pajarillo, blanco como la nieve" que "cantaba tan dulcemente", atrae a Hänsel y Gretel, hambrientos, a su casita de pan y azúcar, que nuestra América golosa hará de chocolate: “- Hola, pequeñines, ¿quién os ha traído? Entrad y quedaos conmigo, no os haré ningún daño. Y, cogiéndolos de la mano, los introdujo en la casita, donde había servida una apetitosa comida: leche con bollos azucarados, manzanas y nueces. Después los llevó a dos camitas con ropas blancas, y Hänsel y Gretel se acostaron en ellas, creyéndose en el cielo. La vieja aparentaba ser muy buena y amable, pero, en realidad, era una bruja malvada que acechaba a los niños para cazarlos, y había construido la casita de pan con el único objeto de atraerlos. Cuando uno caía en su poder, lo mataba, lo guisaba y se lo comía; esto era para ella un gran banquete."3

Es también la filosofía el astuto lobo que -según la "moraleja" que agrega Perrault a su versión de Caperucita Roja- engatusa jóvenes con palabras melifluas, no sólo en el temible bosque, sino también en sus casas y alcobas. ${ }^{4} \mathrm{Y}$ en sus aulas. Pero, icarajo!: "quién no sabe que esos lobos empalagosos / de todos los lobos son los más peligrosos."5

\footnotetext{
${ }^{2}$ Ortiz Rescanière, Alejandro: "El Mito de la Escuela". En: OSSIO, Juan: Ideología mesiánica del mundo andino. Lima, Ignacio Prado Pastor, 1971. “(...) Los niños tuvieron mucho miedo y escaparon. Desde entonces, todos los niños deben ir a las escuelas. Y (...) a casi todos los niños no les gusta la escuela, se escapan." (El relato original es en quechua. Hay traducción portuguesa comentada de José Ribamar Bessa Freire (UERJ): "A representação da escola em um mito indígena".

http://periodicos.proped.pro.br/index.php/revistateias/article/viewFile/64/65

${ }^{3}$ Véase: http://www.grimmstories.com/es/grimm_cuentos/hansel_y gretel

${ }^{4}$ Perrault usa el término "ruelles" que se aplica al pasillo que queda entre la cama y la pared.

${ }^{5}$ On voit ici que de jeunes enfants,

Surtout de jeunes filles Belles, bien faites, et gentilles,

Font très mal d'écouter toute sorte de gens,

Et que ce n'est pas chose étrange,

Sil en est tant que le Loup mange.

Je dis le Loup, car tous les Loups ne sont pas de la même sorte;

Il en est d'une humeur accorte,

Sans bruit, sans fiel et sans courroux,

Qui privés, complaisants et doux,

Suivent les jeunes Demoiselles jusque dans les maisons, jusque dans les ruelles,
} 
2.

La filosofía, ¿es ya una bestia canora? ¿ha devorado ya suficientes ruiseñores?

Parece que no.

Si se ha definido por un canon (aunque éste incluya algún ave canora), muerde excluyendo. Vomita todo aquello que no puede "pasar" por el gañote, lo que no entra en la lista, aquello a lo que no se le puede pasar lista: lo que no puede asimilar.

Quiero decir, no es antropófaga -en el sentido brasilero del término- que conformara y fortaleciera su propio corpus con aquello distinto que come. No se hace humana de trigo, de arroz o de maíz. O de churrasco. No se nutre de la valentía del corazón enemigo, no se alimenta de su agudeza, no aprovecha su saber, no se apropia de su energía, no digiere su punto de vista incompatible con el propio: "no come carne inteligente" (como el guaraní que caza, libre), sino "carne cebada" (domesticada, engordada dentro de alambrados).

No es lo que engulle porque, perversa, sólo se alimenta de sí misma hasta atragantarse. Lo que no puede tragar, lo escupe. Entonces, repetitiva, se teje y desteje, se come y se reconcome en eterno aburrimiento.

Construye academias cerradas. Saciada consigo misma, espera pacientemente que los demás o entren y se hagan como uno, o mueran de hambre. Ella, simplemente, cierra las puertas. Les pone candados y trabas para celebrar tranquila y sin culpa, su magnífica fiesta de disfraces, mientras, afuera, el mundo muere. Confía que ningún Poe pueda introducir la máscara de la muerte roja.

Pero, claro, la peste es ella misma. Y apesta. Contamina todo. 
Recita en las escuelas siempre el mismo verso del universo; sin reverso ni diverso. Si la sacan de ahí, no cambia su modo de comer. se encierra en bibliotecas, museos, torres de marfil. Mastica su rabia en las mazmorras en que encierra libres. Espera. Cuando la vuelven a poner, ya tiene construidos sus sabios muros académicos por donde podrían correr siete carros al mismo tiempo y ya sabe que no puede evitar que la muerte se la lleve.

Enseñará eso, muerte. A quienes sean lo suficientemente capaces de entender, es decir, a quienes acepten regirse por las rígidas normas formales de su rigor mortis, que, sin embargo, no se ablanda aunque críe gusanos.

No es que todos aprendan. No es que se los quiera, de veras, comer. Es que quiere que mueran de hambre. Es que los quiere borrar. Quemar sus toldos ignorantes e inocentes, preguntones y creativos. Y, si no lo hace del todo, no es porque no quiera o no pueda. Es que los necesita para seguir viviendo y reproduciendo su vida de lobo, de bruja, de Naupa Machu, de dragones guardianes de tesoros disecados. Es decir, para seguir viviendo sin convivir, sin cambiar, sin dudar, sin discutir, sin crear.

Para seguir viviendo sin filosofar.

3.

\section{¿Y si bastara un solo ruiseñor para un canto no bestial?}

¡Ah! Ya no sería un ruiseñor -que vaya uno a saber qué ave nocturna es-; ni qué tan parecido su canto al de la lechuza, puro ojo, pura garra, pura rapiña.

Sería, quizás, una calandria mañanera o un sabiá madrugador cantando al amanecer. Esos bichos que la bestia no puede tragar y que, aun regurgitados, siguen cantando, como dicen estos versos de Circe Maia, profesora de filosofía de Tacuarembó:

\section{Por detrás de mi voz}

- escucha, escucha -

otra voz canta. 
Viene de atrás, de lejos;

viene de sepultadas

bocas, y canta.

Dicen que no están muertos

- escúchalos, escucha -

mientras se alza la voz

que los recuerda y canta.

Escucha, escucha;

otra voz canta.

Dicen que ahora viven

en tu mirada.

Sostenlos con tus ojos,

con tus palabras;

sostenlos con tu vida

que no se pierdan,

que no se caigan.

Escucha, escucha;

otra voz canta.

No son sólo memoria,

son vida abierta,

continua y ancha;

son camino que empieza.

Cantan conmigo,

conmigo cantan. 
Dicen que no están muertos;

escúchalos, escucha,

mientras se alza la voz

que los recuerda y canta.

Cantan conmigo,

conmigo cantan.

No son sólo memoria,

son vida abierta,

son camino que empieza

y que nos llama.

Cantan conmigo,

conmigo cantan.

¿Pero cómo? ¿Puede entonces haber $-\mathrm{y}$ de hecho, hay- un filosofar alternativo que escucha y canta con otra voz que viene de atrás, de lejos, viene de sepultadas bocas, y canta? ¿Puede haber un filosofar juntos, mismo en el Liceo Departamental de Tacuarembó? ¿Un filosofar dolido y sonriente, suave y sólido, maternal y potente? ¿Puede ser poesía? ¿Puede acompañarnos en nuestros exilios? ¿Puede levantarlo por el mundo en música y canto, como "una bandera de trigo, de pan y de vino", César Viglietti?

¿Puede el filosofar en el aula ser estética, es decir, experiencia sensible, a la vez que pensante, pensante porque sintiente? ¿Un pensar sustentado en el sentir y vivir pasando peligros juntos?

Si así fuera, desde siempre y para siempre, filosofar sería el más vasto canto poético humano: pensar sintiendo, vivir pensando, uno y los demás, todos y yo; los que están, nomás, los que están de más; los que no están más. 
Una transformación poética del filosofar; una transmutación educativa del filosofar; un cambio filosófico del educar(se) y del politizar; un cambio poético de lo poiético; una reformulación homérica y América, patética pero épica, de lo que somos y no somos los que aquí estamos y hacemos en nuestras teorías, nuestras praxis y nuestras poíesis.

\section{Escucha, escucha.}

Son otras voces. No la voz del Maestro, del Amo, que, harto de escucharse, de querer ser "comme Maître et seigneur de la Nature", 6 de tanto dar 500 horas semanales, ha "perdido la voz haciendo clases". ${ }^{7}$ Y ahora: escucha.

Como ha sido sordo por vanidad, habrá de aprender de los sordos a escuchar a los acallados, analfabetizados, empobrecidos, humillados, asesinados, esclavizados, ninguneados. Como se ha hecho ciego, habrá de aprender a ver y a leer a los invisibilizados. Empezando por los que tiene al lado. Los que tienen hambre y le piden limosna de comida y de conocimiento.

Seguramente, si es maestro, profesor, será visto como rico. Como dice el testimonio de una maestra uruguaya que escucha a un niño:

Acá arriba todo está limpio, allá abajo, todo está sucio. Arriba están los ricos.

\section{¿Quiénes son los ricos?}

Están los ricos que se hacen los ricos y los ricos como usted que viene a trabajar con nosotros. ${ }^{8}$

Si no escucha bien, si no lee bien, empezará, quizás por querer dar, por querer hacer rico y limpio a aquel pobre sucio.

Se sentirá angustiada quizás por la dura tarea que la espera: no sólo "darle pescado; enseñarle a pescar". No sólo darle su comida sino instrumentos para

\footnotetext{
${ }^{6}$ Descartes, Discurso del método, VI parte.

${ }^{7}$ Parra, Nicanor: Autorretrato. (Conozco varias versiones diferentes: ¿habrá una original? ¿será mejor que las otras?)

${ }^{8}$ Sarthou, Danae y Puyol, Ruben: Reconsiderando la educación en Uruguay. Montevideo, edición de los autores, 2013.
} 
conseguirla o hacerla. Y herramientas y armas intelectuales para que piense como uno, el pobre: Alfabeto y Aristóteles; Kant y Marx; habilidades y competencias para salir de la pobreza, para no reproducir generacionalmente la pobreza (o para que los pobres no se reproduzcan tanto) o, al menos, para aprender a vivir con escasos recursos.

Caso se ha dado de quien llevó un niño indígena a su casa para criarlo como a un hijo; lavarlo, vestirlo, blanquearlo, darle juguetes de niño blanco. Y hubiera seguido en eso si no se le hubiera aparecido a la puerta el padre -indígena, indigente- a decirle buenamente: "Si no me lo da ya, la denuncio por secuestro".9

Claro, escuchar y leer a los demás sin hacer trampas es difícil. No es fácil encontrar en ellos "lindas riquezas". ${ }^{10}$ Más lindas que las nuestras. No es fácil abrirse a sus experiencias, hacer del aula un lugar de convivencia humana de mutuos aprendizajes, de creación conjunta de un mundo nuevo en un espacio humano limitado. Pero tópico, actual, no utópico. Filosófico, no aherrojado por La Filosofía.

Aunque la utopía, quizás, consista en creer en la posibilidad de ir generando esas topías.

5. ¿Y si muchos sabiás siguieran cantado junto con otras voces, sepultadas o insepultas, aunque la bestia (escuela, televisión, violencia, hambre) siga devorando el filosofar que quiere saber, en nombre de una "filosofía sabia" que jamás será filosofía ni sabiá?

MLC 30 de agosto de 2013.

\footnotetext{
${ }^{9}$ Ahora que lo pienso, mi abuela crió a una negrita, seguramente nieta de esclavos, cuya madre no podía sostenerla y por eso, en vez de pedirle limosna, como siempre, se la dio. Desde siempre son los pobres quienes dan a los ricos. Hasta los hacen ganarse el cielo: "¿Cómo podré ir al cielo si hay Reforma Agraria? -me decía en mi juventud, honestamente, la hija de un estanciero- ¿Cómo podría hacer obras de caridad si no hubiera pobres?"

10 "Hombre de lindas riquezas: / guitarra, amigos, canción". (Atahualpa Yupanqui: Don Luis Acosta García, "lindo nombre pa un cantor / que anduvo de pago en pago / y en ninguno se quedó")
} 